Article

\title{
Revealing Cultural Ecosystem Services through Instagram Images: The Potential of Social Media Volunteered Geographic Information for Urban Green Infrastructure Planning and Governance
}

\author{
Paulina Guerrero ${ }^{1,2}$, Maja Steen Møller ${ }^{1, *}$, Anton Stahl Olafsson ${ }^{1}$ and Bernhard Snizek ${ }^{3}$ \\ ${ }^{1}$ Department of Geosciences and Natural Resource Management, University of Copenhagen, 1958 Frederiksberg C, \\ Denmark; E-Mails: paulinaguerrero1@gmail.com (P.G.), masm@ign.ku.dk (M.S.M.), asol@ign.ku.dk (A.S.O.) \\ ${ }^{2}$ Institute of Environmental Planning, Leibniz Universität Hannover, 30060 Hannover, Germany; \\ E-Mail: guerrero@umwelt.uni-hannover.de \\ ${ }^{3}$ metascapes.org, 1752 Copenhagen, Denmark; E-Mail: bs@metascapes.org \\ * Corresponding author
}

Submitted: 1 March 2016 | Accepted: 5 May 2016 | Published: 6 June 2016

\begin{abstract}
With the prevalence of smartphones, new ways of engaging citizens and stakeholders in urban planning and governance are emerging. The technologies in smartphones allow citizens to act as sensors of their environment, producing and sharing rich spatial data useful for new types of collaborative governance set-ups. Data derived from Volunteered Geographic Information (VGI) can support accessible, transparent, democratic, inclusive, and locally-based governance situations of interest to planners, citizens, politicians, and scientists. However, there are still uncertainties about how to actually conduct this in practice. This study explores how social media VGI can be used to document spatial tendencies regarding citizens' uses and perceptions of urban nature with relevance for urban green space governance. Via the hashtag \#sharingcph, created by the City of Copenhagen in 2014, VGI data consisting of geo-referenced images were collected from Instagram, categorised according to their content and analysed according to their spatial distribution patterns. The results show specific spatial distributions of the images and main hotspots. Many possibilities and much potential of using VGI for generating, sharing, visualising and communicating knowledge about citizens' spatial uses and preferences exist, but as a tool to support scientific and democratic interaction, VGI data is challenged by practical, technical and ethical concerns. More research is needed in order to better understand the usefulness and application of this rich data source to governance.
\end{abstract}

\section{Keywords}

cultural ecosystem services; e-governance; geosocial mapping; green space governance; spatial analysis; VGI

\section{Issue}

This article is part of the issue "Volunteered Geographic Information and the City", edited by Andrew Hudson-Smith (University College London, UK), Choon-Piew Pow (National University of Singapore, Singapore), Jin-Kyu Jung (University of Washington, USA) and Wen Lin (Newcastle University, UK).

(C) 2016 by the authors; licensee Cogitatio (Lisbon, Portugal). This article is licensed under a Creative Commons Attribution 4.0 International License (CC BY).

\section{Introduction}

It is widely recognized that the presence of urban nature is indispensable for a well-functioning and hospitable city (Beatley, 2011). Today, urban nature or urban ecosystems are often conceived in relation to the concept of green infrastructure (GI). GI is a planning approach which links all types of urban nature together in a network which provides numerous benefits, or ecosystem services, such as: offering a recreational role in everyday life, playing an important part in conserving biodiversity, adding to the cultural identity of a city, easing and improving the environmental quality of the city, and providing natural solutions to technical chal- 
lenges such as sewage treatment in cities (Andersson et al., 2014; Braquinho et al., 2015; Lovell \& Taylor, 2013). It is also generally understood and scientifically proven that $\mathrm{Gl}$ in cities offers health benefits such as alleviating mental, physical and social pressure-as well as being associated with economic benefits (Secretariat of the Convention on Biological Diversity, 2012; Tzoulas et al., 2007). The health benefits, aesthetic enjoyment and recreational opportunities of GI can be conceived as Cultural Ecosystem Services (CES) (Andersson, Tengö, McPhearson, \& Kremer, 2015; Millennium Environmental Assessment, 2005). Thus, CESs connect nature to human values and behaviour and can act as gateways for improving urban sustainability (Andersson et al., 2015). However, the perceptions of CESs are likely to differ as they are dependent on the social context and personal values compared to, for example, the market or scientifically defined recognition of the value of food production or the carbon dioxide intake of a tree (DeFries et al., 2005). While some ecosystem service categories are more tangible which facilitates their economic and biophysical valuation, CES values are more difficult to measure and often call for the use of more holistic and innovative approaches and methods (Gómez-Baggethun et al., 2013).

However, as beneficial as $\mathrm{Gl}$ is, it faces constant competition for inclusion in urban planning and decision-making. Competition for space, adequate valuation, and prioritisation on political agendas are just some examples of the actual and future hurdles (Braquinho et al., 2015). According to Mussachio (2013), there is currently a need to further identify the relationship between ecosystem provisions, human values and perceptions. In other words, citizens must connect with their urban nature for landscape sustainability to genuinely take root in a city (Andersson et al., 2015; Mussachio, 2013). Hence, cities will have to innovate and find ways to incrementally and aptly value urban nature, as well as better understand the complexity of ecosystems and how citizens are already experiencing the nature available to them. An enhanced understanding of the distribution of valuable urban $\mathrm{Gl}$ features as perceived by citizens may be the key to the improved maintenance and management of natural resources. This, however, remains challenging particularly when it comes to CESs (Casalegno, Inger, DeSilvey, \& Gaston, 2013) as they do not come in easily tangible measures, but are rather dependent on individual perceptions. The use of technologies such as social media and smartphones may represent a way around these challenges as they create interactive channels for broad civic participation and new ways to deliver valuable public and scientific information (Brown \& Kyttä, 2014; Linders, 2012).

Volunteered Geographic Information (VGI), which is defined as the use of a range of technologies to create, assemble, and disseminate geographic information (Goodchild, 2007), makes up the dataset for this study.
These data are voluntarily provided by individuals and may come from social media services, wikis, and other media, and are, therefore, often associated with Citizen Science (Jiang \& Thill, 2015). This individualised and dynamic information represents a notable shift in the "content, characteristics and modes of geographic information creation, sharing, dissemination and use" (Sui, Goodchild, \& Elwood, 2013, p.9). With this data source in mind, engaging citizens in governance set-ups using modern technology should not be too complicated: in this example from Copenhagen, an Instagram hashtag (\#) campaign created more than 50,000 responses online on Instagram.

Instagram is an online mobile application focused on sharing photographs and providing a platform for social networking. Instagram enables its users to share pictures taken with a smartphone camera publicly with a hashtag (\#), if the user wishes. Instagram is owned by Facebook (C) and is forming a global community that shares more than 60 million photos every day (Instagram, 2016a, 2016b).

The challenging part really appears to be the act of translating such data into useful, scientifically reliable results. This paper explores such possibilities with a particular focus on CES patterns.

\subsection{Study Aim}

This study explores how harvesting, analysing and interpreting user-generated geographic urban nature images stemming from social media can potentially add to a modern $\mathrm{Gl}$ governance set-up based on digital data sharing. Thus, the study aims to demonstrate an innovative approach to analysing the character of different urban nature areas as represented by nonexperts. This approach might be helpful for understanding how urban ecosystems are used and may also add to inclusive governance by visualising and attributing cultural ecosystem services to GI. In the following, we demonstrate our approach to harvesting and analysing VGI data from the Instagram API through the hashtag \#sharingcph.

This is achieved by studying: firstly, whether shared Instagram images may be used to obtain information about urban nature in a city; secondly, by investigating spatial patterns of shared images which deal with urban nature; thirdly, by showing how this new type of spatial data relates to the formal $\mathrm{Gl}$ in terms of public green and blue spaces, and; finally, to discuss the future potential role of social media VGI for supporting urban planning and the promotion of CES in a city (i.e., e-governance).

\subsection{Volunteered Geographic Information and E-Governance}

Due to rapidly developing information and communication technologies, the opportunities for broad stake- 
holder inclusion are becoming more numerous since these technologies can act as tools to support communication between government and citizens. Today, most citizens in the western world have access to the Internet and thanks to devices such as smartphones with online access and embedded sensors, the generation of data is unprecedented (Batty, 2013; World Bank, 2016). This shift is adding new ways and perspectives to knowledge sharing and knowledge gathering that can support the development of ideas and practices regarding urban planning and governance. Online and smartphone applications have the potential to act as media for transparent, democratic, inclusive and situation-based participatory processes of interest to planners, citizens/users, politicians and scientists.

Due to many technological advances such as ubiquitous smartphones and free applications, our societies are currently in a situation where we have the ability to "keep track of where everything (and everyone) is in real time" (Sui et al., 2013, p. 3). These advances, as poignantly expressed by Sui et al. (2013) and Johnson and Sieber (2013), have "unleashed the potential of a geographer within everybody" (Sui et al., 2013, p. 9) and created a society which can "act as sensors of their environment" (Johnson \& Sieber, 2013, p. 66) or social sensing as Liu et al. (2015) puts it. Geo-referenced citizen science is part of the big data phenomenon, which has experienced explosive growth in the past few years and is "transforming all aspects of governments, businesses, education and science" (Sui et al., 2013, p. 3). The majority of this big data information is "data pertaining to activities that humans are intimately involved with", i.e. everyday actions of personal value (Batty, 2013, p. 275). Several services such as Twitter and Instagram combine geo-referenced images and short texts. Via Application Programming Interfaces (APIs), anyone can access these images and perform text and spatial analysis.

VGI is an information rich resource, which is publicly available and is shared directly by users thereby creating an enormous database (Goodchild, 2007; Jiang \& Thill, 2015). Clearly this information is valuable for branding and marketing purposes, and has been used in research, e.g., tourism, disaster relief and transportation planning (Damiano, Pau, \& Lehtovuori, 2015; García-Palomares, Gutiérrez, \& Mínguez, 2015; Roche, Propeck-Zimmerman, \& Merikskay, 2011; Sui et al., 2013), but it is also interesting for a broad base of social, spatial and behavioural sciences as it often links experiences with time and place. Its applications are just beginning to unfold and explorative research, such as this study, is harnessing this potential. Urban planners and governments are looking to incorporate new technological trends, and VGI not only provides an opportunity to connect and communicate with citizens, but this data can be further analysed to investigate behaviours, trends and issues which arise, or are already present, in a city (Tasse \& Hong, 2014).
When governments connect with the VGI community it can result in a mutually beneficial relationship between governments and citizens and can in turn "support greater transparency, efficiency, and effectiveness of government services" (Johnson \& Sieber, 2013 , p. 65). The concept of e-governance deals with this type of interaction and is defined as technologymediated relationships between citizens, government and businesses facilitation, i.e. communication, policy evolution, and the democratic expression of the will of citizens (Marche \& McNiven, 2003; Stock, 2011). Egovernance situations range from citizens influencing a government by delivering information that helps it to be more responsive and reflective, to government acting as a facilitator for citizens' actions and to situations where citizens self-organise and co-produce informal arrangements without the government playing an active role (Linders, 2012). Cities can connect with VGI communities through formal or informal processes and may involve tools and mechanisms that allow citizen participation (Johnson \& Sieber, 2013).

\subsection{Social Media VGI and Cultural Ecosystem Services (CES)}

A special type of VGI is geo-referenced social media data originating from sources such as Twitter, Facebook or Instagram, which is sometimes referred to as ambient geospatial information ("AGI") (Stefanidis, Crooks, \& Radzikowski, 2013). According to Batty (2013), inherent and intimate personal value is attached to what is shared via social media (Batty, 2013; Jiang \& Thill, 2015). Thus, social media VGI reflects a connection and a shared experience with one's surroundings, while an additional strength is that it comes directly from citizens themselves (Johnson et al., 2013). VGI is creating a new medium for communicating information that circumvents traditional paths and which can help to fill a gap in available data. An example of this is social media VGI data consisting of digital photographs with geotags and related semantics or tags. However, the ability to quantify or even conceptualize VGI remains limited (Feik, Roche, \& Sui, 2013). As such, the possibilities for analysis rest with innovative and evolving methods.

Examples of such innovative methods are studies which illustrate how social media data from non-experts can be mined (Feick et al., 2013), and studies which link CESs to VGI stemming from social media to map and reflect these services (Casalegno et al., 2013; Leetaru, Wang, Cao, Padmanabhan, \& Shook, 2013; Pastur, Peri, Lencinas, García-Llorente, \& Martín-López, 2016). Hence, recent studies have shown that geo-tagged online images provide an effective metric for mapping the key components of CESs, and that the concept of image sharing contains an attached value that can be spatially analysed (Casalegno et al., 2013; Pastur et al., 2016).

However, so far, to our knowledge, no studies have 
explored the potential of linking social media VGI to CESs in an urban setting. Combining the fact that cities and urban CESs can be considered drivers for environmental awareness (Andersson et al., 2015) and the fact that most VGI originates from urban settings (Haklay, 2013), social media VGI is, thus, a data source which is rich in spatial, temporal, quantitative and qualitative information the application of which to urban planning demands to be explored (Casalegno et al., 2013; Damiano et al., 2015; Pastur, et al., 2016).

\section{Data and Methods}

This section presents the geosocial data derived from Instagram, the methods applied and a classification based on images, steps in geo-processing and finally the application of diverse spatial analysis methods.

\subsection{Data Acquisition and Study Area}

The city of Copenhagen, defined as the administrative municipalities of Copenhagen and Frederiksberg, acts as the study area (Figure 1). As of 2015, the city of Copenhagen had an urban population of 743,564 inhabitants and an area of $179.29 \mathrm{~km}^{2}$ (Statistics Denmark, 2015).

In 2014, Copenhagen was named the Green Capital of Europe by the European Commission. As a consequence of this award, the city of Copenhagen initiated a "sharing" concept with the purpose of promoting and communicating sustainable solutions. A Sharing Copenhagen office was established to facilitate partnerships between privates, organisations and the City of Copenhagen (Isherwood, 2013). This office launched the \#sharingcph campaign by inviting people to share images of Copenhagen online on social media, by tagging them \#sharingcph. The message was distributed by events, websites and posters in the city. The \#sharingcph campaign generated more than 50.000 images online (not all with geo-location). The willingness of the citizens to participate led to the wish or idea that the rich data could be transformed into something more than just pictures online, but how exactly to do so was unclear to the Sharing Copenhagen office. The Sharing Copenhagen office expressed a wish to be able to give the data back to the citizens as well as an interest in what we, as urban researchers, would be able to extract from the \#sharingcph images ( $M$. Møller \& B. Snizek, personal communication, January $27,2015)$. Based on these motivations, we explored the possibilities of extracting, analysing and applying the data derived from \#sharingcph to urban planning.

All Instagram images tagged with \#sharingcph were retrieved via its API (Instagram, 2016a, 2016b) and stored in a PostGIS geodatabase (Obe \& Hsu, 2015). This data included links to the images stored on Instagram, their text, the date they were taken and their geographical locations. 37,329 Instagram images taken in the period July $1^{\text {st }} 2012$ to March $25^{\text {th }} 2015$ were retrieved.

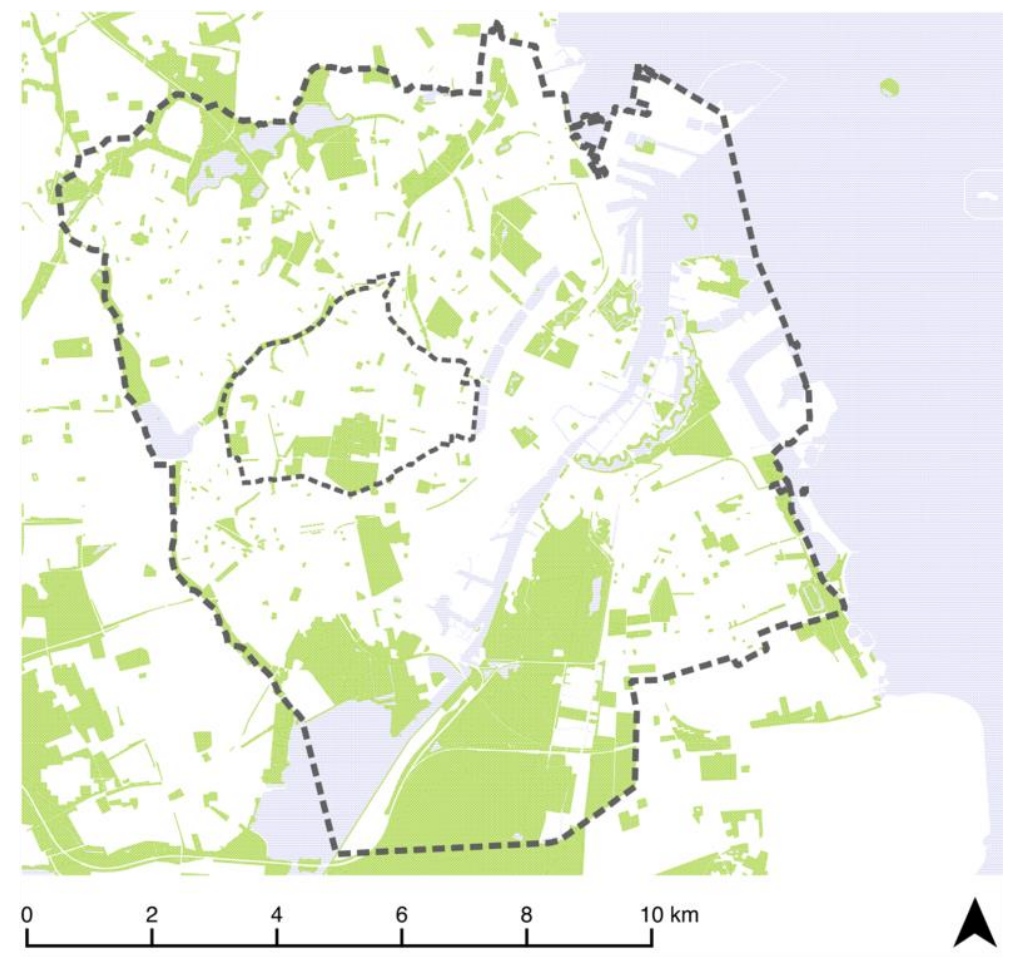

Figure 1. The study area consists of the central part of the Copenhagen region, which is defined as the administrative delineation of the municipalities of Copenhagen (outer dashed line) and Frederiksberg (inner dashed line). Officially designated blue and green spaces form the central building blocks of the city's Urban Green Infrastructure. Source: Municipality of Copenhagen. 
As the search also returned images from outside the boundary of Copenhagen, only the 22,500 (N) georeferenced images located within the study area were finally selected (Table 1). While 22,500 images make a very solid data basis, we had to select a smaller sample of these for a more detailed analysis of image content, i.e. a categorisation of the images (described below). A sample size of at least 2,397 images would allow one to make predictions about this image population with a $95 \%$ confidence level, assuming a $+/-2 \%$ margin of error and a standard deviation of 0.5 . Therefore, the final categorised total number of images was 2,572 (n).

According to Statistics Denmark, in 2014, 24\% of Danes were using Instagram, a noticeable increase from the result of a 2013 survey, which found that only $12 \%$ of Danes had an Instagram account (Statistics Denmark, 2015; YouGov, 2013). The 2013 survey also states that the average user spends two hours and 55 minutes on Instagram per week (YouGov, 2013). The population $(\mathrm{N})$ consisted of 1,131 users who contributed between 1 to 890 images each to the dataset; the average number of images per user being 17.4. The final sample of images ( $n$ ) was shared by a total of 944 individuals with an average of 2.7 images posted per user. This low average number of images per user was retrieved by setting a threshold of max. 50 images per user, thereby allowing for a more distributed sample in relation to the number of users.

\subsection{Categorisation of Images}

A reliable image categorisation had to be carried out to identify the shared urban nature within the city. An attempt to categorise the images automatically based on related \#tags was conducted, but it did not produce a satisfactory outcome compared to a manual classification of the image content. Hence, a manual classification of the images was performed instead. As $\mathrm{Hu}$, Manikonda and Kambhampati (2014) highlighted, determining the relevant image content categories is a challenge as images contain richer features compared to text. Since we wanted to study urban nature, we chose to apply a framework of lay people's nature definitions based on Buijs and Volker's Dimensions of the Prototypicality of Nature (Buijs, 2009). This categoryscheme aims to be inclusive and incorporate the many ways in which nature is defined, perceived and interpreted by lay people (Buijs, 2009). Buijs and Volker's categories are: (1) Elements, (2) Spontaneous nature,
(3) Productive Nature, (4) Designed Nature, and (5) Domesticated Nature (Buijs, 2009). We added a sixth category Biocultural Nature in order to cover situations with images of a visible human-nature interaction, such as nature-based recreation (Figure 2).

A web-based categorising interface was developed, which made it possible to categorise images into the categories mentioned fairly quickly simply by clicking on one button per image. The interface is designed to include the image that was posted, a map of the location where it was uploaded and the semantics associated with the post (i.e., in order: image-mapsemantics-buttons). To be able to filter away the images that were not representative of nature and give the person conducting the classification the option to choose from the images which were not of nature or did not fit into any class, the classes (1) Not an Urban Nature Image, and (2) I Don't Know were added.

Figure 3 is an example of the online interface; in this case, the selected category was Designed Nature.

A three-step hierarchical how-to guide was produced to further elucidate the categorisation process (see Table 2). Two researchers then hand-categorised the pictures via the online medium according to the previously mentioned categorisation system. Based on this categorisation, the categorised sample size (n) was obtained.

In order to conduct an assessment of the reliability of this categorisation, two external researchers were informed about the categorisation scheme and were given the hierarchical guide and asked to categorise 498 of the pictures which had been randomly selected and previously categorised. To achieve a $95 \%$ confidence level and a confidence interval of 4 , a total of 487 images had to be assessed; thus, the 498 images that were categorised for the assessment is above the required sample. This reliability assessment returned a $73.1 \%$ match with the previous categorisation, leaving $26.9 \%$ in disaccord. The majority of the images that were in disaccord ( $41 \%$ or 54 of the 498 images) were not categorised as urban nature, but had been categorised as green in the reliability assessment round. With $73.1 \%$ of the images categorised under the same category, this indicates that while the categorization scheme was of use for this data set, individual interpretation in any manual categorization will always play a role and will never be exact. Additionally, the number of categories could be a hindrance as this creates more options and in turn more variability.

Table 1. Basic description of Instagram images, number of users who have shared the images (i.e. Instagram users), and the range of images per user in the original, geo-referenced, and final sample of categorised images.

\begin{tabular}{llll}
\hline & Harvested & $\begin{array}{l}\text { Geo-referenced in City } \\
\text { (study area) }\end{array}$ & $\begin{array}{l}\text { Sample size of categorised } \\
\text { images }\end{array}$ \\
\hline Number of images & 37,329 & $22,550(\mathrm{~N})$ & $2,572(\mathrm{n})$ \\
Number of users & 1,173 & 1,131 & 944 \\
Images posted per user & Min =1, Max =893 & Min =1, Max =890, Avg =17.4 & Min =1, Max =50, Avg =2.69 \\
\hline
\end{tabular}




\begin{tabular}{|c|}
\multicolumn{1}{c|}{ THE } \\
ELEMENTS \\
\hline SEA \\
SUN \\
WATER \\
\\
\\
\end{tabular}

\begin{tabular}{|c|c|}
\hline $\begin{array}{l}\text { SPONTANEUS } \\
\text { NATURE }\end{array}$ & $\begin{array}{l}\text { PRODUCTIVE } \\
\text { NATURE }\end{array}$ \\
\hline GAME & LANDSCAPES \\
\hline WILD PLANTS & MEADOWS \\
\hline MEADOW BIRDS & FIELDS OF MAZE \\
\hline Moss & (AGRICULTURAL) \\
\hline & OCEAN \\
\hline INSECTS & \\
\hline FUNGUS & \\
\hline CITY BIRDS & \\
\hline WEEDS & \\
\hline & \\
\hline & \\
\hline
\end{tabular}

\begin{tabular}{|c|c|}
\hline $\begin{array}{l}\text { DESIGNED } \\
\text { NATURE }\end{array}$ & $\begin{array}{l}\text { DOMESTICATED } \\
\text { NATURE }\end{array}$ \\
\hline WOODED BANKS & COWS \& PIGS \\
\hline ROAD VERGES & DOGS \& CATS \\
\hline CITY PARKS & HOUSE PLANTS \\
\hline GARDENS & ZOO ANIMALS \\
\hline ALLOTMENTS & \\
\hline URBAN TREES & \\
\hline SWALES & \\
\hline $\begin{array}{l}\text { RETENTION } \\
\text { PONDS }\end{array}$ & \\
\hline CANALS & \\
\hline BEACH AREA & \\
\hline
\end{tabular}

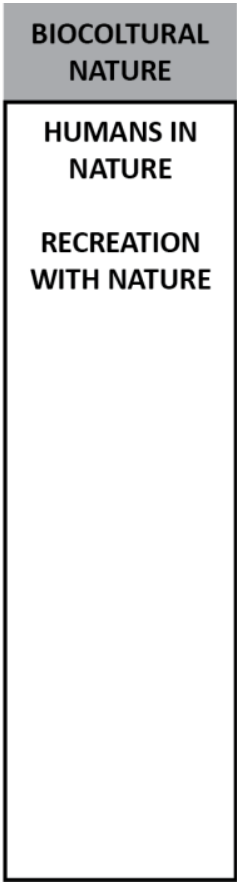

Figure 2. The used image categorization classifies urban nature into six categories based on Dimensions of Nature. Examples of image content are shown below for each urban nature category. Adapted from Buijs (2009).

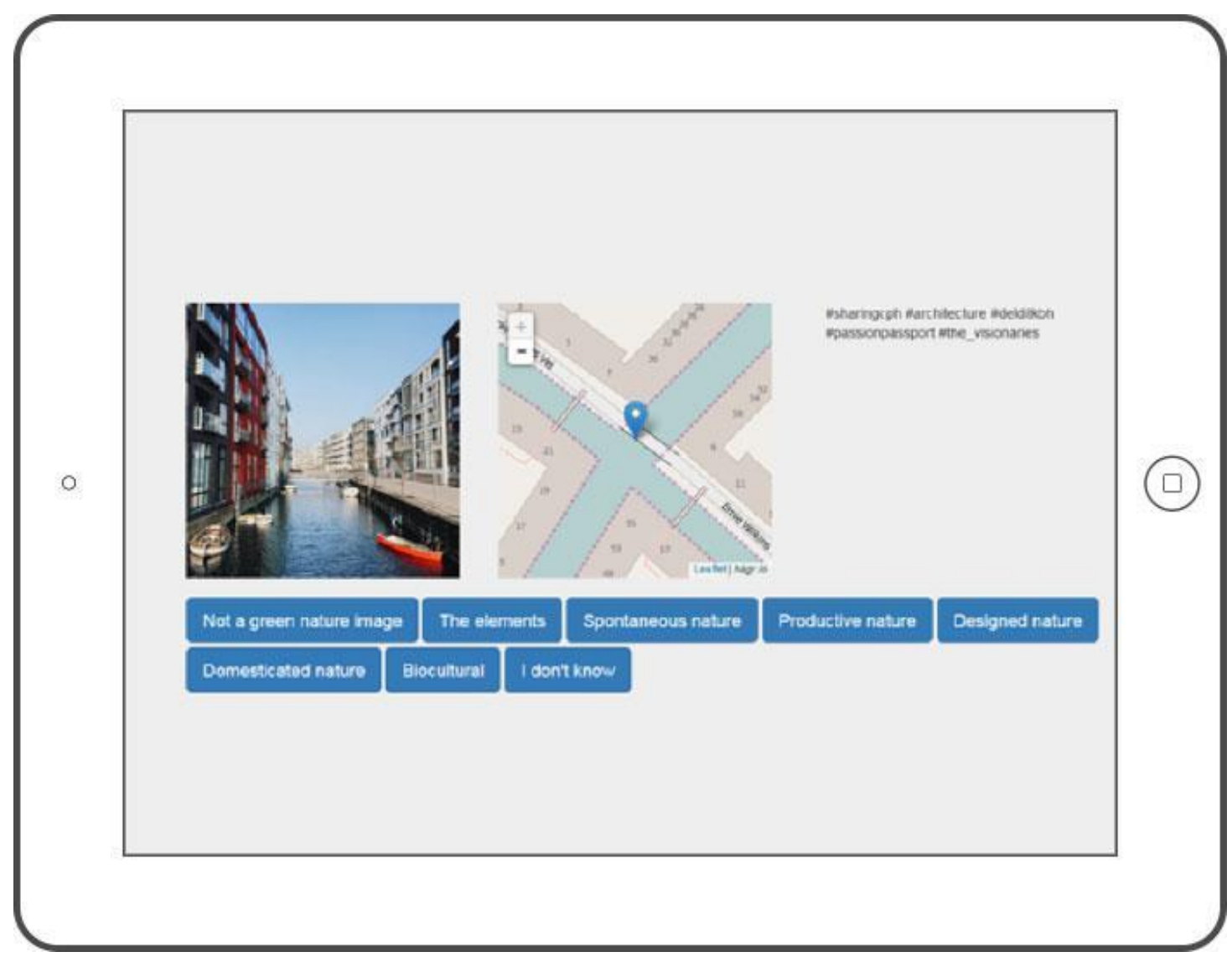

Figure 3. Example of the categorization interface showing the image, the location it was taken in, its text and the eight categorization options. 
Table 2. A three-step hierarchical how-to guide was produced to clarify the categorisation process.

\begin{tabular}{lll}
\hline Step & $\begin{array}{l}\text { Hierarchy Guide for Urban Nature } \\
\text { Categorisation }\end{array}$ & Elaboration and general examples \\
\hline 1 & $\begin{array}{l}\text { Identify main focus of image and categorise } \\
\text { based on Urban Nature or Not Urban Nature }\end{array}$ & $\begin{array}{l}\text { A picture of a bike resting against a wall is not urban } \\
\text { nature. However, a bike in a green space comes under the } \\
\text { Designed Nature category. } \\
\text { Puddles that reflect an urban setting are not urban } \\
\text { nature. There must be a reflection of nature present, e.g., } \\
\text { a tree. }\end{array}$ \\
& $\begin{array}{l}\text { A swan in a park is spontaneous nature (the swan) and } \\
\text { not designed nature (the park). } \\
\text { When multiple options are possible, more }\end{array}$ \\
& $\begin{array}{l}\text { A tree in the foreground of e.g., a church, and as the main } \\
\text { focus of an image, is categorised as designed nature. }\end{array}$ \\
& Amage. & $\begin{array}{l}\text { An image of an urban scene with slight vegetation present } \\
\text { (i.e., leaves) with semantics relating to the presence of } \\
\text { the vegetation is urban nature, e.g., \#leaf, \#autumn. }\end{array}$ \\
\end{tabular}

Table 3. Categorisation result of the content analysis.

\begin{tabular}{lll}
\hline Description & Categorised sample $\mathbf{( n = 2 , 5 7 2 )}$ & Urban Nature images $\mathbf{( n = 8 7 4 )}$ \\
\hline Image Content & Not Urban Nature, 64.8\% & Designed Nature, 42.6\% \\
& Urban Nature, 34\% & The Elements, 27.2\% \\
& Unable to be categorised, 1.2\% & Biocultural, 13.7\% \\
& Spontaneous, 9.8\% \\
& Domesticated, 3.9\% \\
& Productive, 2.7\% \\
\hline
\end{tabular}

\subsection{Spatial Data Analyses}

Spatial analyses were only performed on the sample size of 2,572 images (n). The category, I Don't Know representing $1.2 \%$ of the data, was omitted from the spatial analyses.

The data points, i.e., images, were processed into and analysed via GIS. A spatial calculation (spatial join) and visualisation was conducted in order to observe and compare the distribution of urban nature images in relation to all images and in relation to the official green infrastructure (with a $50 \mathrm{~m}$ buffer to include images taken in border zones with a view of the urban nature site). Further, a hotspot analysis was conducted to reveal clusters of images. In this analysis, the radius was set to 400 metres with a threshold value of nine images; hence, all image clusters with more than nine images were considered a hotspot. Finally, a distance analysis was performed to explore the spatial character of the data in more detail. The distance of each urban nature image from the city centre-derived as the centroid from the city centre's boundary polygon-was calculated with the Hub Distance Tool. This analysis returned a vector layer that connects each point to the specified central hub. The length of each line was calculated and this data was analysed for frequency at specific kilometres and a corresponding histogram was generated. In other words, the analysis returned the number of images found at specific distances from the city centre. This facilitated the identification of distances from the centre where a relatively high or low number of images had been shared, i.e., peaks and valleys of shared urban nature in the city.

\section{Results}

This section presents the results of the data analyses.

\subsection{Categorisation Result of Urban Nature Related Images}

The results of the categorised process reveal that Urban Nature represents $34 \%$ ( 874 images) of the images in the sample size (Table 3 ). The urban nature images were further classified according to the six perceived dimensions of nature. The 'Designed Nature' category, which includes parks, urban trees, and canals, represented almost half (42.6\%) of the urban nature images. Further, almost $1 / 3$ of the images were classified as the 'Elements', e.g. sunset, while about $10 \%$ of the images were classified as 'Biocultural Nature' (e.g. naturebased recreation) or 'Spontaneous Nature' (e.g. reflections in puddles). Logically, few images were classified as 'Domesticated Nature' or 'Productive Nature'. Some examples of categorised urban nature images are shown in Figure 4. 


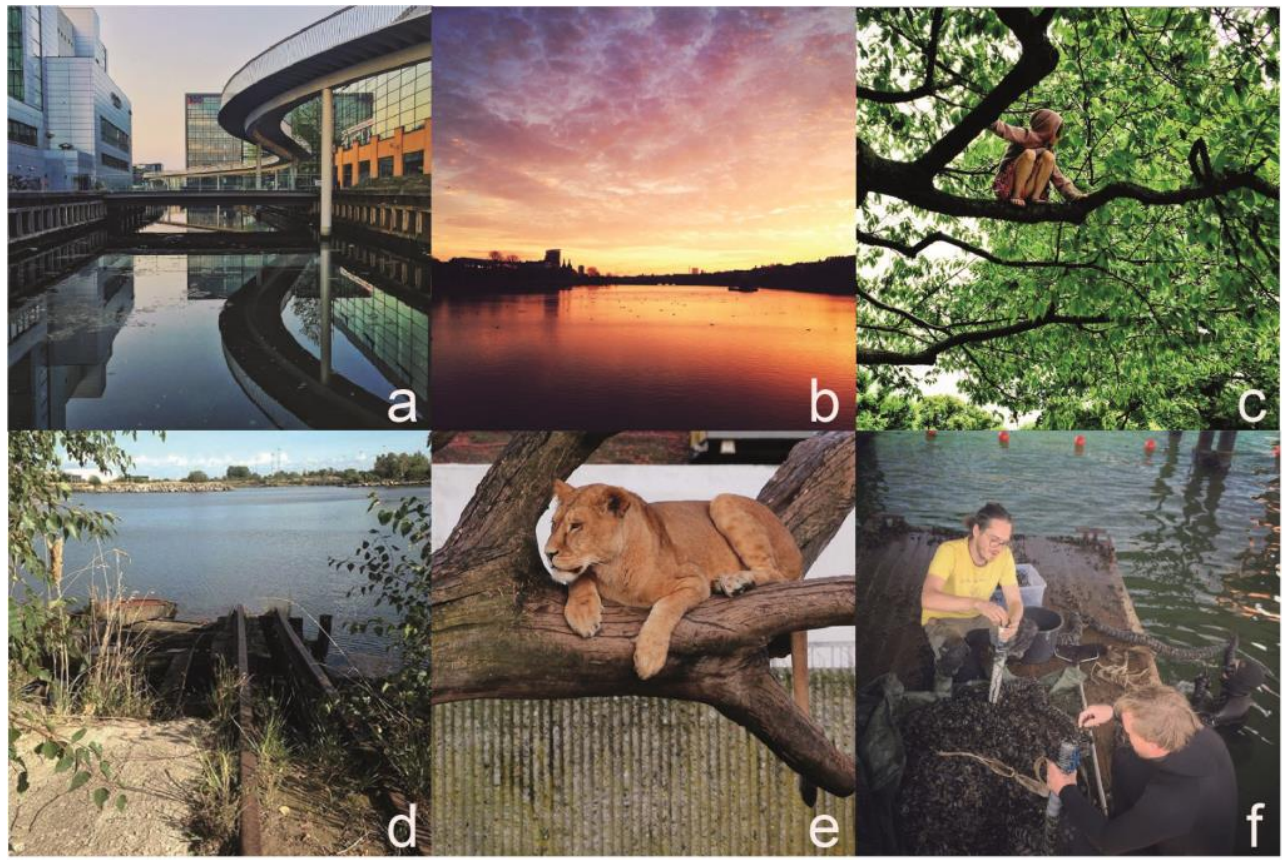

Figure 4. Examples of urban nature images as categorised. Photographer's Instagram user names in parenthesis (starting from top left): a: Designed (@tbsptrsn), b: The Elements (@might_be_wrong), c: Biocultural (@remosteen) d: Spontaneous (@copenhagen_streetlife), e: Domesticated-showing a lion from the Copenhagen zoo (@mmhenriksen), and f: Productive-showing oyster harvest in Copenhagen harbour (@maritimenyttehaver).

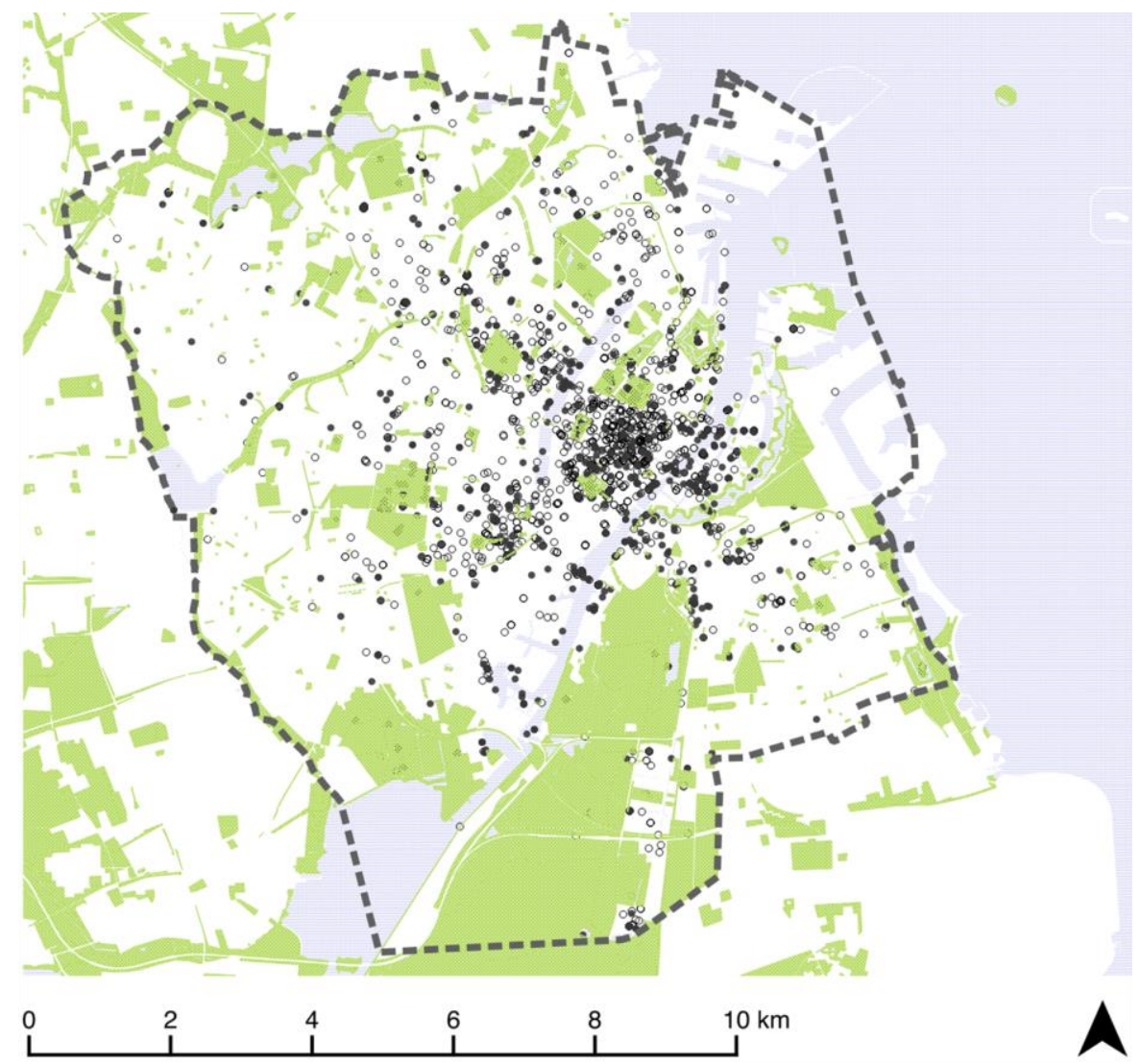

Figure 5. The spatial distribution of Urban Nature (filled symbol) and Not Urban Nature images (outline symbol).

\subsection{Spatial Patterns of Urban Nature}

While Urban Nature images are spatially distributed in the city and similar in distribution to Not Urban nature images, there is a pattern at certain locations to create clusters of images classified as Urban Nature (see Figure. 5).

Of the total number of images, $44.4 \%$ were located 
in green spaces regardless of categorisation, while $63.6 \%$ of the urban nature images were located in green spaces. Thus, the majority of the urban nature images coincided with the managed green spaces of the city; these managed green spaces contain the majority of the shared urban nature images of Copenhagen. On the other hand, $36.4 \%$ of the urban nature images, i.e., about one-third, were located outside the managed urban nature. This provides an interesting perspective as it shows that Copenhageners also share and experience urban nature outside designated public green spaces. Thus, it is of importance for the city to be aware that this nature is of value and is an asset for the city's green infrastructure.

These associations and disassociations with designated green spaces allow city planners to visualise the actual patterns of how citizens share images of the green spaces of the city. Similarly, this relationship between shared urban nature and designated green spaces provides insight which may prove valuable for the management of the urban nature of a city.

\subsection{Hotspots of Urban Nature Images}

A hotspot analysis was applied to identify areas with a high number of urban nature images and areas with a low number. The hotspot analysis returned 19 locations where more than nine images had been taken. To find the total number of images located at these spots, the attributes were selected by either based on the green spaces layer as borders or on the size of the hotspot. Two of these locations were found to be clusters which were probably due to a user uploading various images indoors, i.e., not at the location where the images had been taken (see upload error in limitations section). These two areas, consisting of a total of 28 images, were thus omitted. The top ten clusters with the highest number of images were then selected and individually analysed to identify their specific location and the number of images at each location. Noticeably, the top ten identified hotspots correspond to locations which are designated as green spaces, see Figure 6 . The number of images taken at the top locations ranged from 13 to 33 .

\subsection{Distance Analysis}

To analyse the data further, a distance analysis was conducted. As previously explained, there was an accumulation of 28 images, both of nature and non-nature; which in order to avoid skewing the spatial location, these images were excluded as they were clearly not spatially representative. Figure 7 is a visualisation of the distance analysis with a radial behaviour of the data with its focal point at the city centre. As the histogram shows, the distance analysis facilitates the identification of specific distances from the centre where a high or low number of images had been shared, i.e., peaks and valleys of shared urban nature in the city, see Figure 8.

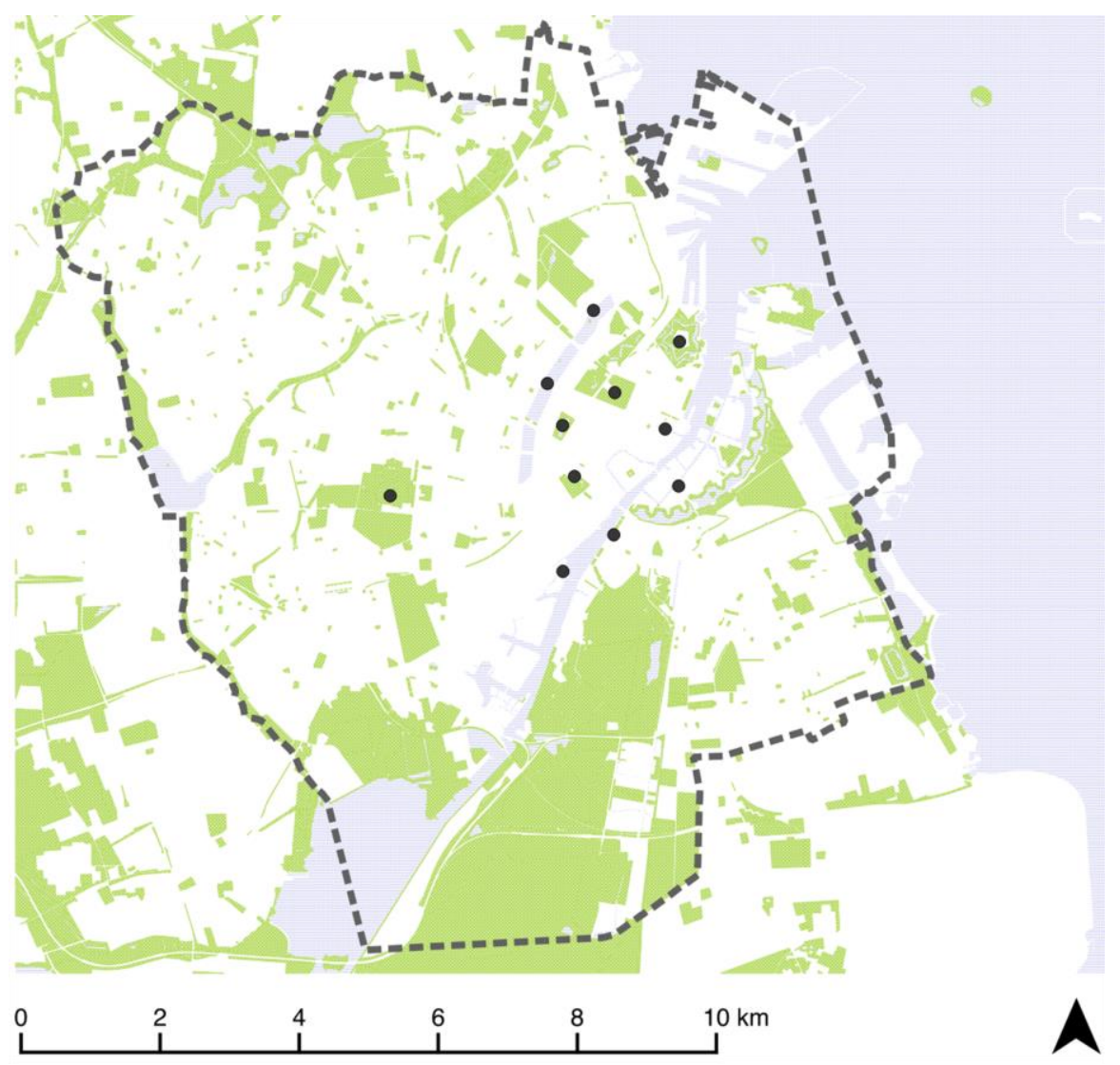

Figure 6. Top 11 Nature Hotspots relative to public green and blue spaces. 


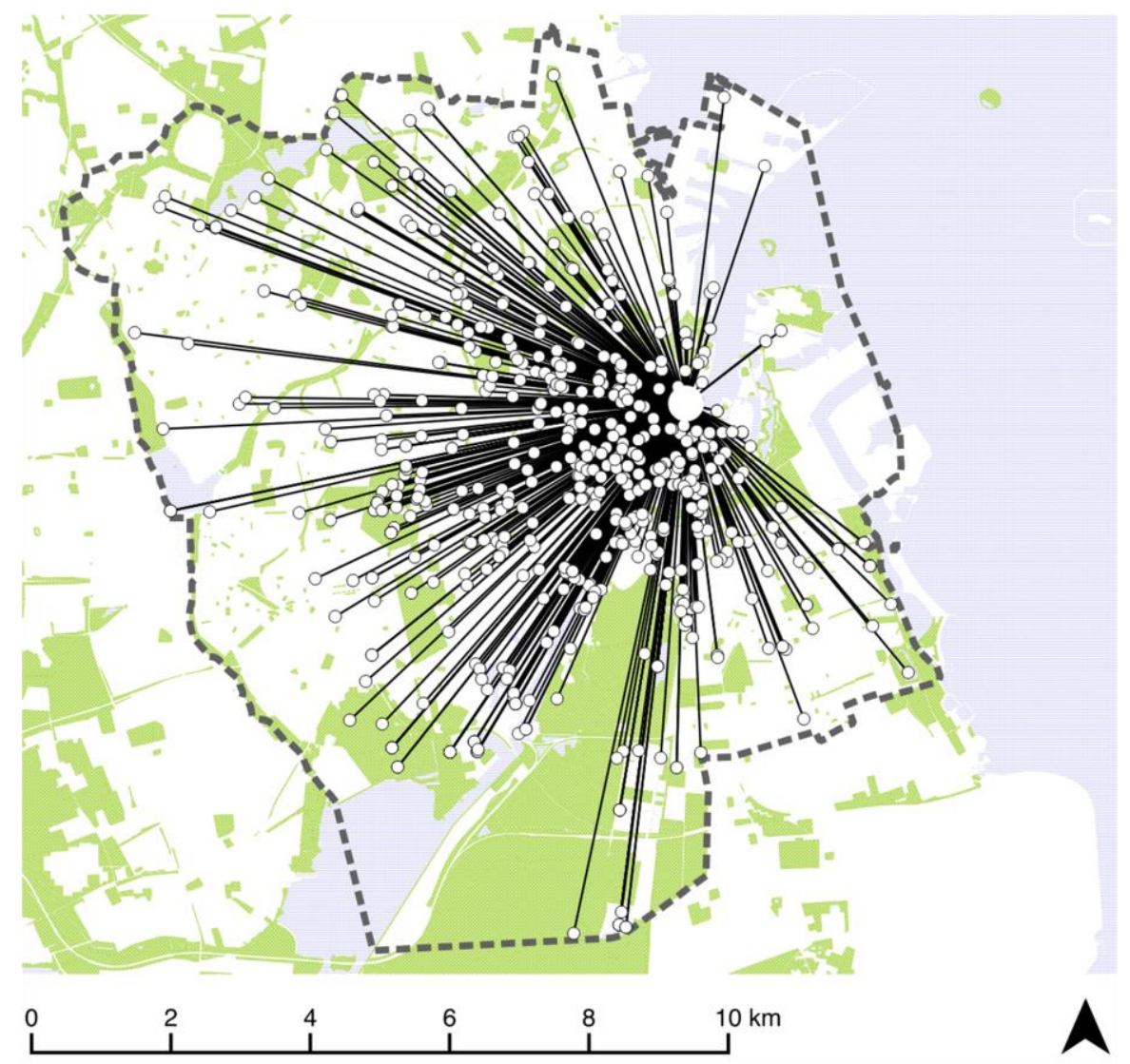

Figure 7. Images' relation to the city centre of Copenhagen.

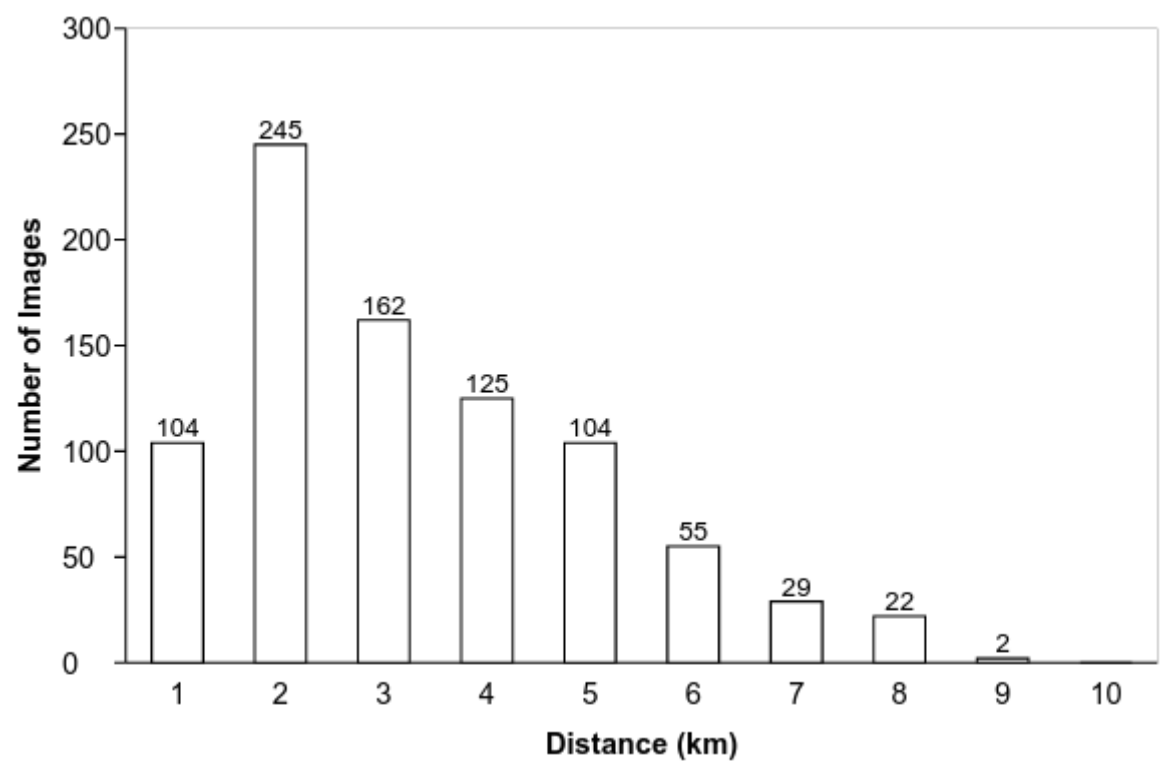

Figure 8. Urban Nature images in relation to distance from Copenhagen's city centre $(r=-0.86)$.

The outcome of this analysis shows that more information, i.e., images, regarding urban nature will probably come from areas near the city centre rather than from the outer realms of the city. People have an affinity for sharing images from these central parks. Future research could focus on attempting to determine the causes of this affinity, which may include accessibility, park features or leisure use. As the histogram shows, the peak seen at 2 to $3 \mathrm{~km}$ from the centre could also be explained by the actual green space structure of Copenhagen's parks as key green spaces are located approximately $2 \mathrm{~km}$ from the city centre.

\section{Discussion}

The images from this study constitute a valuable 
source of VGI data and provide relevant information about the spatial representation of Copenhagen's urban nature in an Instagram dataset. Of all the aspects Copenhagen inhabitants could have shared about their city in \#sharingcph, $34 \%$ of the images represented Urban Nature. It also shows that a general mobile application such as Instagram can be used to collect VGI content and present urban nature patterns in a city (Tasse \& Hong, 2014).

Casalegno et al. (2013) showed that CES can be mapped with geo-referenced social media images and suggested that shared urban nature images, which serve as proxies for CESs such as aesthetics or sense of place, have an attached value and can be used as a tool for gathering and analysing this information (Casalegno et al., 2013: Stedman, Beckley, Wallace, \& Ambard, 2004). This study supports the conclusion that CESs can be mapped via shared urban nature images.

This research is related to works of other methodologies that utilise images such as Visitor Employed Photography (VEP), in order to obtain an understanding of people's perceptions of parks and natural environments by interpreting their photographs (Mackay \& Couldwell, 2004). Even though the image-taking method is controlled in VEP, this VGI method is in line with the idea that photographs can be analysed to identify a sense of place, attachment, aesthetics and other factors pertaining to the human-environment interaction in natural spaces (Garrod, 2007; Mackay \& Couldwell, 2004; Stedman et al., 2004). The analysis of images can provide valuable information as photographs can be considered "representations of specific attributes of various dimensions of (an) experience" (Garrod, 2007, p. 14). According to Stedman et al. (2004), photographs offer insight into specific historical, cultural and social ways of seeing the world and these images can standalone as data sources since they are expressions of the ideas themselves. In other words, while surveys and interviews can provide great insight, images can capture certain perspectives, emotions and attitudes such as a sense of place, aesthetic value and attachment (Stedman et al., 2004).

Considering images as proxies for CES, this research supports the assertion that VGI can be used to identify places that people share due to the CES offered (Casalegno et al., 2013; Pastur et al., 2016). The MEA includes inspiration, aesthetic values, sense of place, and recreation and tourism among the CES nature provides (Millennium Ecosystem Assessment, 2005). As such VGI images, which are free expressions of people's perception of nature whether it is the inspiring, aesthetic or sense of place service provided, can be used as CES proxies. For example, the top urban hotspots of this study can be considered green spaces with high CES. A city authority can use this data as a driver for protection and investment in these areas as the information is coming from those benefiting from the services (Sherrouse, Clement, \& Semmens, 2011).

This area of research and methodologies are still nascent and further explorative research focused on extended objectives must be explored to make any definite findings. For example, the fact that a low number of images were taken in a particular area does not necessarily mean that no perceived urban nature value is present, but rather indicates that other variables, e.g., accessibility issues, might be obstacles (Jiang \& Thill, 2015). Further, it should be noted that spatial distributions of most activities extracted from social sensing data are positively correlated with population density (Liu et al., 2015). An overarching key consideration in visualising and analysing VGI is simply that it highlights patterns and information-here Instagram images - that are already present (Tasse \& Hong, 2014).

$44.4 \%$ of the total number of shared images was taken in the green spaces of Copenhagen; furthermore, $63.6 \%$ of the green images came from these locations. This city provides numerous green spaces for its citizens and aims to promote the accessibility of these spaces for its citizens in order to promote humanenvironment interactions. According to 2012 data, $80 \%$ of Copenhageners lived at a distance of 300 metres from a green area (European Green Capital, 2012). People have access to the green spaces in their city and, as this study shows, they share images from these locations. There is currently a call to incorporate GIS methods into urban planning as this provides a more tangible way of representing issues regarding humanenvironment interactions (Kabisch, Qureshi, \& Haase, 2015). Through the spatial representation of urban nature VGI in Copenhagen, we use GIS to analyse these interactions and green space social values.

The distance analysis reveals a distinct centrally based radial-pattern with regards to the VGI data originating in Copenhagen, i.e., within a $2-3 \mathrm{~km}$ radius of the city centre. Accordingly, this study shows that urban nature VGI of Copenhagen is not evenly dispersed throughout the city; there are hotspots and specific spatial behaviours. As such, spatial patterns in the data and user-representability, among others (see limitations), need to be addressed and understood if social media VGI is to be used in decision-making.

While VGI is considered separate from public participation geographic information system, or PPGIS, it is nevertheless a related field (Brown \& Kyttä, 2014). VGI analysed through GIS "research and practice remains embryonic," and consequently, this study follows the call for experimental design in methodology (Brown et al., 2014). This method of mapping CES based on a large set of publicly shared images, while notably passive, i.e., voluntary, answers the call to increase public participation rates in PPGIS ecosystem services mapping (Brown \& Kyttä, 2014). The VGI data obtained from large sets of social media is "understood in the context of big data" (Sui et al., 2013, p.4). For ES map- 
ping, this is of enormous value as the use of smartphones and social media applications will increase, which will enhance the quantity and representability of this data source for future research. As such, by exploring this field, this study aims to improve our understanding of the mapping of ecosystem services so that ecosystem services become more highly valued and to support green decision-making in urban settings.

The spatial representation of CES shows the localisation of highly valued ecosystems, as well as, the identification of "critical focal areas for cultural services management" (Plieninger, Dijks, Oteros-Rozas, \& Bieling, 2013, p. 119). Additionally, the ability to map cultural - in addition to the provisioning and regulating services of a city gives a more complete picture of ES, as well as a comparison of the ecosystem services at play (Plieninger et al., 2013). Interestingly, Pastur et al. (2016) also indicates that social media image data may potentially help to spatially visualise and monitor the medium and long-term conditions and trends of CES (Pastur et al., 2016). In the same way as remote sensing helps to identify critical areas of land use change that affect provisioning and regulatory ES, with this data we are also able to monitor changes in cultural ecosystem services by social sensing (Liu et al., 2015).

Another advantage of using geo-referenced images is that they offer a means of determining CES values that are hard to capture with just words such as aesthetics or sense of place (Pastur et al., 2016; Stedman et al., 2004). Integrating CESs into urban planning has been problematic due to their intangibility, complex relationships with biophysical variables and the difficulty connected with attributing values (Pastur et al., 2016). This research illustrates that VGI from social media provides information, in many cases unarticulated but present, about a city's urban nature and its CESs. This research complements other studies which propose methods to integrate and value CESs in decisionmaking processes (Casalegno et al., 2013; Pastur et al., 2016; Plieninger et al., 2013).

\subsection{VGI Use for Urban Planning and E-Governance}

This study seeks to provide insights into addressing the potential of using social media VGI for the assessment of CES in urban planning and governance.

In a time where a growing number of cities around the world comply to open data politics following concepts such as 'Smart Cities' and more citizens navigate and interact online, an increasing interest of mining and understanding and using these digital data is seen in science, politics and planning (Huijboom \& Van den Broek, 2011; Kitchin, 2014). VGI as a volunteered, information-rich data source can help to illuminate the (nature) pulse of a city, i.e., what, where and how urban nature is 'shared'. Such information could be useful for urban planners who may be able to use it as a driver for development or maintenance projects as they could gain better understanding of how citizens 'react' to e.g. urban nature. The information holds relevance in planning and design processes because it provides a potential plethora of information regarding local and detailed knowledge about spatial conditions and characters as well as social connections. Such information can be used to better understand city dynamics, i.e. uses and preferences in given urban spaces (Seeger, 2008). Another outcome of VGI when integrated in planning and politics is that citizens may be empowered by 'sharing' if they thereby become involved in solutions to better understand, protect, and develop their environment. Relating the use of VGI to the urban CES framework may allow planners, not only to value urban nature more effectively, but also to adequately plan and protect a city's biodiversity and its citizens' well being.

VGI is a means of communication that is just starting to be used to create new responsive relationships between governments and citizens and it may lead to an increased level of citizen participation in decisionmaking (Johnson \& Sieber, 2013). According to the 2014 UN E-government Report, both developed and developing countries are at the decisive point of embracing the potential role that mobile interaction will play in people's everyday lives (United Nations Egovernment Survey, 2014). In terms of social media, there is a wealth of information which is already being interpreted and used by its creators, i.e., the citizens themselves. This provides a cost-effective way for governments to engage with citizens in "e-decision making and co-creation of service" (United Nations Egovernment Survey, 2014). When properly planned and structured, VGI data allows governments to react to citizens' values and concerns (Johnson \& Sieber, 2013).

As a dataset like this represents a quite abstract or 'free' approach as to what can be shared within the \#sharingcph theme, one could imagine that similar campaigns could be targeted at more specific themes or places. In such cases, pre-defined hashtags could be used to getting closer to an auto-categorization of the images into themes or clusters. A simple example could be \#cphpark with the sub hashtags \#like or \#dontlike, which would already classify images into positive or negative categories.

The concept of facilitated VGI ( $f-$ VGI) is a variation of VGI that may be of interest to planners or others who wish to get input to a predefined topic or area. FVGI is a way to operationalize and focus VGI data into public participation in planning. As explained by Seeger (2008), an f-VGI process is facilitated by e.g. a planning professional, a local organization or government in order to feed VGI into a pre-established planning or design process (Seeger, 2008). The \#sharingcph campaign can be understood as a form of $\mathrm{f}-\mathrm{VGI}$, as it was developed and promoted by the City of Copenhagen. How- 
ever, as mentioned in the beginning of this paper, the team behind the campaign did not plan for any particular way of feeding the data into further processes regarding urban planning and design. This 'freely' formulated campaign made the dataset both interesting and challenging to work with because inputs were it not guided in any particular direction (other than "share your city").

The data is characteristic by being differentiated as each photo with the \#sharingcph tag represents an individual person's experience somewhere in the city. In combination with other datasets that e.g. inform on participants' geo-social backgrounds, VGI holds potential as it can seemingly reach a broad audience as well as new user groups that are often weakly represented (Seeger, 2008).

In this study we focused particularly on the spatial references to map out the data while the content of the photographs and \# semantics were used to back-up the understanding of the visual content. The temporal aspects of the data were not in focus of this study, but could be important in other studies when exploring use of green spaces in different seasons/over time.

VGI data can consist of highly refined, differentiated, and personal impressions from participants who share it. The challenge is to find suitable ways to analyse such data and to evaluate the impact of different levels of facilitation or steering of processes where VGI feeds in and ways to harness VGI data in combination with other datasets. VGI data could be corroborated by other established data collection methods such as surveys and interviews to create a more robust data set (Pastur et al., 2016). The distinct data sources can complement each other as the VGI has valuable strengths in that it provides large, spatially referenced and unbiased information, i.e., no potential bias triggered by interviewers (Pastur et al., 2016). Currently, in the US, younger age groups tend to use Instagram the most (Duggan, Ellison, Lampe, Lenhart, \& Madden, 2015). Therefore, while not yet representative of the general public, this highlights a potential strength, as it is often difficult to involve this demographic group in governmental decision-making processes.

This study coincides with previous research on VGI and suggests that planners can use this data to: 1) uncover already present CES patterns, 2) plan and monitor future changes, 3) aid in the management and prioritisation of green spaces and, 4) establish efficient and effective communication with citizens (Casalegno et al., 2013; Johnson \& Sieber, 2013; Pastur et al., 2016; Tasse \& Hong, 2014).

\subsection{Limitations}

The use of geo-referenced, freely available social media data as a proxy for studying spatial trends in distinct fields is a rapidly growing and interesting field
(Casalegno et al., 2013; Leetaru et al., 2013; Pastur et al., 2016; Tasse \& Hong, 2014; Tuhus-Dubrow, 2014). However, questions relating to the limitations and reliability of this data source cannot be ignored.

This study focused on identifying spatial patterns in the data and did not aim to study individual users. Thus, because these data are publicly available, the issue of anonymity and privacy arises. It was also considered that some users might not be aware of the privacy settings or the sharing of their locations; thus, neither specific user data, nor analyses of such were generated. As no information was gathered concerning the users, no socio-economic data exist, which makes it difficult to assess representability in detail-which is a limitation of this study.

Currently, the demographic limitations of the data are quite noticeable and as such, it is not entirely representative of a population. As previously mentioned, in Denmark, only $24 \%$ of the population had an Instagram account in 2014 (Wijas-Jensen, 2014). Additionally, when working with VGI, it is wise to bear in mind that empirical research often involves 'participation inequality' with some participants contributing far more than others (Haklay, 2013). Areas with higher population densities or greater levels of outdoor activity also reflect higher geographical citizen science participation (Haklay, 2013). Tech-savvy and higher income groups are generally over-represented (Damiano et al., 2015). So while the demographics of social media and VGI participation are currently skewed, it is expected that with the predictable increase in the use of smartphones and social media, this medium of communication will indeed become more popular and more inclusive (Damiano et al., 2015).

State of the art and software have a high spatial reliability (Leetaru et al., 2013). However, sometimes there is a discrepancy between the location where an image was taken and where it was uploaded. This may be explained by people taking pictures, but waiting until later to upload and share them (Damiano et al., 2015) or perhaps their devices not being able to upload immediately due to, e.g. network problems. Unfortunately, no specific studies were found that analysed this problem. To counter this issue, the categorisation contained a map that showed the location of the images. This issue was seldom isolated in our dataset. However, regarding specific spatial analyses in this study, clusters of noticeable erroneous Instagram images with upload location errors that would skew the data were individually analysed and if needed omitted (see hotspot methodology for further information).

The data quality and locational accuracy of VGI for CES representation must be analysed and improved upon. This includes identifying location upload errors, such as identical, numerous uploads from an indoor location (see methodology section) or distance difference (i.e., range) of image to an actual feature. For ex- 
ample, this research made sure to view each image in a detailed content and spatial context such as 'green images located within green spaces' to ensure that only nature images were included. However, for the general population this was not implemented as there were not spatial analysis based on the population, N, and errors are to be expected. Albeit, the locational accuracy is an issue in the field of georeferenced image analysis. Solutions such as "integrating the (actual) location into the image assignment" (i.e., computing the distance difference) have been mentioned (Sun, Fan, Bakillah, \& Zipf, 2013). For now, concepts such as meticulous observation of images, a sample tests to find error factors, clear categorization and boundary setting are initial solutions to overcome location errors. Where possible, buffers were included to partly compensate for some of the distance range discrepancy.

This data set was obtained solely based on the \#sharingcph hashtag which, as previously described, was promoted by the City of Copenhagen as a part of its EU Green City campaign. This specific selection facilitated a focus on urban planning due to the city sharing motivation behind the campaign and hashtag. Furthermore, this study aimed to incorporate the egovernance and urban planning potential for cities from the outset. As such, the \#sharingcph hashtag combined both the city planner's involvement, i.e., promotion of the hashtag, and the VGI aspect. However, the analysis focused on urban nature CESs so the hashtag of choice could have been simply \#nature, or another related hashtag. Undoubtedly, scaling-up the hashtag to include more general terms would give this study a distinct focus, and it would also provide a large data set with interesting potential for CES analysis.

\section{Conclusion}

This explorative study shows that urban nature is indeed shared in a city, with $34 \%$ of shared images of the city representing urban nature. Additionally, the use of social media VGI to obtain this information and spatial knowledge of the city is a field that is currently growing; this study provides input to this research area.

As the name implies, an important feature of VGI data is its spatial content which when adequately analysed can provide trends and patterns about a city; in this study its urban nature. This rich data source, obtained directly from citizens, can be analysed to identify shared urban nature spatial trends and patterns. The results reveal specific behaviour in this data, i.e., hotspots and centrally based radial dispersion throughout the city. Additionally, $44.4 \%$ of the general images were taken at managed green spaces and urban nature images show a $63.6 \%$ alignment with these green spaces. The spatial tendencies of this data coincide with the official green spaces, yet there exists shared urban nature images, $36.4 \%$, that are found in non-official green spaces. This study shows that the spatial patterns of VGI data are valuable and rich in information about urban nature and human-environment interactions, yet it is critical to first understand the data's spatial distribution in order to make further assumptions about its meaning. Urban planners can use urban nature VGI to promote CES in a city. The data helps to understand the value and interaction of humans and nature in a city and may act as a direct conduit for participation and communication between citizens and government.

Finally, as this data-set is very context specific, we would like to stress the importance of conducting future studies which attempt to determine what motivate Instagram users share urban nature images. This would include identifying the specific qualities that lead to the sharing of specific urban nature images (i.e., park accessibility, design configuration, presence of water, etc.), which is key in order to be able to utilise this source of information in city planning and governance. While some research exists regarding motivations and psychological reasons as to why people share, i.e., in order to share a personal cause, further research is needed in this area to determine, e.g. why a certain park feature has been shared, the significance of time availability or the novelty of urban nature with regards to picture sharing.

\section{Acknowledgements}

The authors would like to thank Dr. Reinhard Böcker for his guidance, the City of Copenhagen's Sharing Copenhagen office for their collaboration and the thousands of Instagrammers who provided the data for this research. This project received funding from GREEN SURGE, EU collaborative project, FP7-ENV.2013.6.2-5603567

\section{Conflicts of Interest}

The authors declare no conflict of interests.

\section{References}

Andersson, E., Barthel, S., Borgström, S., Colding, J., Elmqvist, T., Folke, C., \& Gren, A. (2014). Reconnecting cities to the biosphere: Stewardship of green infrastructure and urban ecosystem services. Ambio, 43(4), 445-453.

Andersson, E., Tengö, M., McPhearson, T., \& Kremer, P. (2015). Cultural ecosystem services as a gateway for improving urban sustainability. Ecosystem Services, 12, 165-168.

Batty, M. (2013). Big data, smart cities and city planning. Dialogues in Human Geography, 3(3), 274-279.

Beatley, T. (2011). Biophilic cities: Integrating nature into urban design and planning. Washington DC, United 
States: Island Press.

Braquinho, C., Cvejić, R. Eler, K., Gonzales, P., Haase, D., Hansen, R., . . . Zeleznikar, S. (2015). A typology of green urban spaces, their ecosystem provisional services and demands (GREEN SURGE report D3.1). Retrieved from www.greensurge.eu

Brown, G., \& Kyttä, M. (2014). Key issues and research priorities for public participation GIS (PPGIS): A synthesis based on empirical research. Applied Geography, 46, 122-136.

Brown, H. R., Zeidman, P., Smittenaar, P., Adams, R. A., McNab, F., Rutledge, R. B., \& Dolan, R. J. (2014). Crowdsourcing for cognitive science: The utility of smartphones. PloS one, 9(7), e100662.

Buijs, A. (2009). Different theoretical approaches to study the human-nature relationship. In Public natures: Social representations of nature and local practices (Doctoral dissertation). Wageningen University, The Netherlands.

Casalegno, S., Inger, R., DeSilvey, C., \& Gaston, K. J. (2013). Spatial covariance between aesthetic value \& other ecosystem services. PloS one, 8(6), e68437.

Damiano, C., Pau, H., \& Lehtovuori, P. (2015). A sense of place: Exploring the potentials and possible uses of location based social network data for urban and transportation planning in Turku City Centre. Turku Urban Research Report.

DeFries, R., Pagiola, S., Adamowicz, W.L., Akcakaya, H.R., Arcenas, A., Babu, S., . . . Fritz, S. (2005). Analytical approaches for assessing ecosystem condition and human well-being. Ecosytems and human well-being: Current state and trends by Millenium Ecosystem Assessment. Washington: World Resources Institute.

Duggan, M., Ellison, N. B., Lampe, C., Lenhart, A., \& Madden, M. (2015). Social media update 2014. Pew Research Center, 19.

European Green Capital. (2012). Section 3: Green urban areas Copenhagen. European Green Capital. Retrieved from http://ec.europa.eu/environment/euro peangreencapital/wp-content/uploads/2012/07/Sec tion-3-green-urban-areas_Copenhagen.pdf

Feick, R., Roche, S., \& Sui, D. (2013). Understanding the value of VGI. In D. Sui, S. Elwood, \& M. Goodchild (Eds.), Crowdsourcing geographic knowledge volunteered geographic information (VGI) in theory and practice (pp. 15-30). Chicago, IL: Springer Science \& Business Media.

García-Palomares, J. C., Gutiérrez, J., \& Mínguez, C. (2015). Identification of tourist hot spots based on social networks: A comparative analysis of European metropolises using photo-sharing services and GIS. Applied Geography, 63, 408-417.

Garrod, B. (2007). A snapshot into the past: The utility of volunteer-employed photography in planning and managing heritage tourism. Journal of Heritage Tourism, 2(1), 14-35.

Gómez-Baggethun, E., Gren, Å., Barton, D. N., Lange- meyer, J., McPhearson, T., O’Farrell, P., . . . Kremer, P. (2013). Urban ecosystem services. In Urbanization, biodiversity and ecosystem services: Challenges and opportunities (pp. 175-251). Netherlands: Springer.

Goodchild, M. F. (2007). Citizens as sensors: The world of volunteered geography. GeoJournal, 69(4), 211-221.

Haklay, M. (2013). Citizen science and volunteered geographic information: Overview and typology of participation. In Crowdsourcing geographic knowledge (pp. 105-122). Netherlands: Springer.

Hu, Y., Manikonda, L., \& Kambhampati, S. (2014). What we instagram: A first analysis of instagram photo content and user types. Association for the Advancement of Artificial Intelligence, Arizona: ICWSM.

Huijboom, N., \& Van den Broek, T. (2011). Open data: An international comparison of strategies. European journal of ePractice, 12(1), 1-13.

Instagram. (2016a). Developer. Instagram. Retrieved from https://instagram.com/developer/?hl=en

Instagram. (2016b). About us. Instagram. Retrieved from https://www.instagram.com/about/us

Isherwood, J. (2013). Copenhagen: Inviting the world to see how it's done. The Official Website of Denmark. Retrieved from http://denmark.dk/en/green-living/ copenhagen/green-capital

Jiang, B., \& Thill, J. C. (2015). Volunteered geographic information: Towards the establishment of a new paradigm. Computers, Environment and Urban Systems, 53, 1-3.

Johnson, P. A., \& Sieber, R. E. (2013). Situating the adoption of VGI by government. In Crowdsourcing geographic knowledge (pp. 65-81). Springer Netherlands.

Kabisch, N., Qureshi, S., \& Haase, D. (2015). Humanenvironment interactions in urban green spaces: A systematic review of contemporary issues and prospects for future research. Environmental Impact Assessment Review, 50, 25-34.

Kitchin, R. (2014). The real-time city? Big data and smart urbanism. GeoJournal, 79(1), 1-14.

Leetaru, K., Wang, S., Cao, G., Padmanabhan, A., \& Shook, E. (2013). Mapping the global Twitter heartbeat: The geography of Twitter. First Monday, 18(5).

Linders, D. (2012). From e-government to wegovernment: Defining a typology for citizen coproduction in the age of social media. Government Information Quarterly, 29(4), 446-454.

Liu, Y., Liu, X., Gao, S., Gong, L., Kang, C., Zhi, Y., .. . Shi, L. (2015). Social sensing: A new approach to understanding our socioeconomic environments. Annals of the Association of American Geographers, 105(3), 512-530.

Lovell, S. T., \& Taylor, J. R. (2013). Supplying urban ecosystem services through multifunctional green infrastructure in the United States. Landscape ecology, 28(8), 1447-1463.

MacKay, K. J., \& Couldwell, C. M. (2004). Using visitor- 
employed photography to investigate destination image. Journal of Travel Research, 42(4), 390-396.

Marche, S., \& McNiven, J. D. (2003). E-government and e-governance: The future isn't what it used to be. Canadian Journal of Administrative Sciences/Revue Canadienne des Sciences de l'Administration, 20(1), 74-86.

Millennium Ecosystem Assessment. (2005). Ecosystems and human wellbeing: Current state and trends. Washington, DC: Island Press.

Musacchio, L. R. (2013). Key concepts and research priorities for landscape sustainability. Landscape Ecology, 28(6), 995-998.

Obe, R. O., \& Hsu, L. S. (2015). PostGIS in action. Manning Publications Co.

Pastur, G. M., Peri, P. L., Lencinas, M. V., García-Llorente, M., \& Martín-López, B. (2016). Spatial patterns of cultural ecosystem services provision in Southern Patagonia. Landscape Ecology, 31(2), 383-399.

Plieninger, T., Dijks, Ss, Oteros-Rozas, E., \& Bieling, C. (2013). Assessing, mapping, and quantifying cultural ecosystem services at community level. Land Use Policy, 33, 118- 129.

Roche, S., Propeck-Zimmerman, E., \& Mericskay, B. (2011). GeoWeb and risk management: Issues and perspectives of volunteered geographic information. GeoJournal, 78(1), 21-40.

Secretariat of the Convention on Biological Diversity. (2012). Cities and biodiversity outlook. Montreal, Canada: Secretariat of the Convention on Biological Diversity.

Seeger, C. J., (2008). The role of facilitated volunteered geographic information in the landscape planning and site design process. GeoJournal, 72(3-4), 199213.

Sherrouse, B., Clement, J., \& Semmens, D., (2011.) A GIS application for assessing, mapping, and quantifying the social values of ecosystem services. Applied Geography, 31(2), 748-760.

Statistics Denmark. (2015). Population in Denmark. Statistik Denmark. Retrieved from http://www.dst. $\mathrm{dk} / \mathrm{en} /$ Statistik/emner/befolkning-og-befolkningsfre mskrivning/folketal

Stedman, R., Beckley, T., Wallace, S., \& Ambard, M. (2004). A picture and 1000 words: Using resident- employed photography to understand attachment to high amenity places. Journal of Leisure Research, 36(4), 580-606.

Stefanidis, A., Crooks, A., \& Radzikowski, J. (2013). Harvesting ambient geospatial information from social media feeds. GeoJournal, 78(2), 319-338.

Stock, W. G. (2011). Informational cities: Analysis and construction of cities in the knowledge society. Journal of the American Society for Information Science and Technology, 62(5). 963-986.

Sui, D., Goodchild, M., \& Elwood, S. (2013). Volunteered geographic information, the exaflood, and the growing digital divide. In Crowdsourcing geographic knowledge (pp. 1-12). Netherlands: Springer.

Sun, Y., Fan, H., Bakillah, M.,\& Zipf, A. (2013). Roadbased travel recommendation using geo-tagged images. Computers, Environment and Urban Systems, 53, 110-122.

Tasse, D., \& Hong, H. (2014). Using social media to understand cities: Carnegie Mellon Research Showcase. Proceedings of NSF workshop on big data and urban informatics. Retrieved from http://repository.cmu. edu/cgi/viewcontent.cgi?article=1271\&context=hcii

Tuhus-Dubrow, R. (2014, October 21). Will Twitter revolutionize how cities plan for the future? Next City. Retrieved from https://nextcity.org/daily/entry/urb an-planning-twitter-social-media-data

Tzoulas, K., Korpela, K., Venn, S., Yli-Pelkonen, V., Kaźmierczak, A., Niemela, J., \& James, P. (2007). Promoting ecosystem and human health in urban areas using green infrastructure: A literature review. Landscape and urban planning, 81(3), 167-178.

United Nations E-government Survey. (2014). Egovernment for the future we want. New York: United Nations: Department of Economic and Social Affairs.

Wijas-Jensen, J. (2014). It-anvendelse $i$ befolkningen. Copenhagen, Denmark: Danmarks Statistik.

World Bank. (2016). Internet users (per 100 people). The World Bank. Retrieved from http://data.worldbank. org/indicator/IT.NET.USER.P2/countries?display=map

YouGov. (2013). Sociale medier 2013: Danskernes holdning til og brug af sociale medier. YouGov. Retrieved from https://yougov.dk

\section{About the Authors}

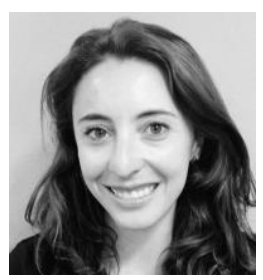

Paulina Guerrero has a double-degree master's in Environmental Science from the University of Copenhagen and the University of Hohenheim, Germany. She is currently working on her PhD at the University of Hannover in the EU funded PlanSmart Project analyzing ecosystem services and solutions for urban water challenges. She is interested in studying human-nature interactions through spatial modeling and citizen science participation. 

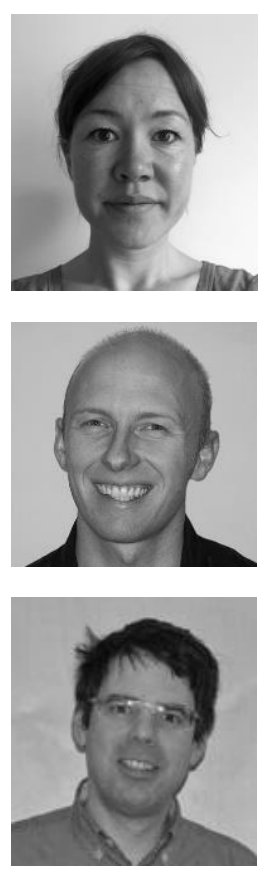

Maja Steen Møller has a master's degree in Landscape Architecture from the University of Copenhagen. She currently holds a position as PhD student within the EU FP7 Project GREEN SURGE based at University of Copenhagen. Her research interests include urban green space governance and the use of digital tools to understand i.e. uses, flows and needs and to facilitate participation and collaboration related to preservation and development of urban green/blue commons.

Anton Stahl Olafsson is Assistant Professor, PhD at the University of Copenhagen with a MSc in Geography. His research interests include GIS and spatial analyses in relation to sustainable planning and management of cities, landscapes, green infrastructure, outdoor recreation, and non-motorised transport. Socio-environmental issues or the linkages between people, society, environment and nature are the core focus of his research. At the moment he acts as project manager in the EU collaborative project GREEN SURGE.

Bernhard Snizek holds a PhD in active transport modeling from the University of Copenhagen and is the CEO of Copenhagen-based metascapes.org. 